\title{
The Man behind the Curtain: Exploring the Role of IS Strategic Consultant
}

\author{
Riccardo Bonazzi, Charlotte Ceccaroli, and Stéphanie Missonier \\ University of Lausanne, Information Systems Institute, UNIL-Dorigny, \\ 1015 Lausanne, Switzerland \\ \{riccardo.bonazzi, charlotte.ceccaroli, \\ stephanie.missonier\}@unil.ch
}

\begin{abstract}
Most organizations encounter business-IT alignment problems because they fail to properly understand how well an enterprise software package aligns with or fits their needs. Strategic consultants make a profit by reducing such external manifestations of the differences between the organization's needs and the system's capabilities. Therefore it appears relevant to understand how consultants behave.

Our theoretical model shows how a consultancy can assess the way to extract and to generalize knowledge from its clients. The share of a consulting firm's global knowledge is compensated with new local knowledge obtained from the client. Hence we underline a way to assess the quality of that contribution and the mutual knowledge exchange.
\end{abstract}

Keywords: IS Strategy, Strategic consultant, Business-IT alignment, ontological distance, design science, business model, knowledge-based theory, Organizational Knowledge Creation theory.

\section{Introduction}

The development, implementation, operation, support, maintenance, and upgrade of enterprise systems (ES) have given rise to a multibillion dollar industry. Nonetheless organizations encounter difficulties in achieving an adequate return on investment since they fail to properly assess the ontological distance between software capabilities and their organizational needs. (Rosemann et al. 2004)

Consultants are often used to reduce the differences between the organization's needs and the system's capabilities. Yet their strategic role in this domain has often been neglected by scholars (Pozzebon and Pinsonneault, 2005; Swanson, 2010). Over a period of more than twenty-six years, the Strategic Management Journal has given large attention to top management teams, and increasingly to middle managers, but has not published a single article on strategy consultants (Whittington 2007). Strategic consultants are sometimes considered magic wizards with unknown power. But the title of this article recalls that even the wizard of $\mathrm{Oz}$ was just a man with a fancy machine behind a curtain. The purpose of this article is to study that fancy machine, and how it can be used to produce magic. 
In the rest of the paper we take a look at IS Strategy, defined as 'the organizational perspective on the investment in, deployment, use, and management of information systems' (Chen et al. 2010, p.237). The aim of this paper is to model IS "strategy as a profession". In doing so we respond to the call by Whittington (2007), and we are interested in the risk reduction by minimization of the ontological distance between software capabilities and their organizational needs identified by Rosemann et al. (2004). The work of a consultant is an example of "strategy as a profession" and it is an archetype of a knowledge intensive firm. The most important assets (key resources) and actions (key activities) that a consultancy must use to make its business model work are worth investigating in detail. In this study we consider Small and Medium Enterprises (SME) offering IS strategic consulting. We ground our theory into practice by presenting the outcomes of a six-month internship in a strategic consulting firm which moved from its start-up status toward SME status by means of a shift toward business process management. Our research question is obtained accordingly:

\section{RQ: How a small/medium strategic consultancy can positively use its expertise to gain a sustainable competitive advantage?}

The main audience for this paper is composed of IS strategic consulting firms, which seek a sustainable advantage based on their core competences. We also hope to raise the interest of Chief Information Officers of companies which are clients of IS strategic consulting firms and which are interested in understanding how IS strategic consulting firms work. Finally we address IS strategy scholars interested in business-IT alignment, hoping to open a set of new directions to be explored. From a theoretical perspective, our model shows part of the elaboration of an IS "strategy as profession" and more precisely how to assess quality. From a practical perspective, our research helps both consultancies and CIOs to understand their work and improve the implementation of a configurable IT. The rest of the paper proceeds as follows. We start by reviewing the existing literature on IS strategic consultancies and identify the gaps to address through a set of research sub-questions. Then we introduce our theoretical model and suggest a set of testable propositions. For the sake of clarity, we address IS scholars and present the instantiation which we intend to use to test our proposition. Then we address to practitioners and describe how our theoretical model can be used in a business model. We conclude with a set of discussions and directions for further research.

\section{Literature Review}

In this section, we present previous works on IS strategic consultancies and assess the gaps in the existing literature to refine our research question into a set of research subquestions. According to Swanson (2010) "while they often appear as players, even major ones, in the IS field's many case studies, consultancies are rarely the focus of the research questions addressed" (p.18). Since this topic is at the cross-road of different disciplines, we present four articles representing the contributions of four research domains. 
Table 1. The constructs of our model

\begin{tabular}{|l|l|l|l|}
\hline \multicolumn{1}{|c|}{ Article } & \multicolumn{1}{|c|}{ Research Domain } & Key activities & \multicolumn{1}{c|}{ Key resources } \\
\hline $\begin{array}{l}\text { Pozzebon, M., \& } \\
\text { Pinsonneault, A. } \\
(2005)\end{array}$ & Resource-Based View & $\begin{array}{l}\text { From global to } \\
\text { local }\end{array}$ & $\begin{array}{l}\text { Global Vs Local Knowl- } \\
\text { edge }\end{array}$ \\
\hline $\begin{array}{l}\text { Werr and } \\
\text { Stjnberg (2003) }\end{array}$ & $\begin{array}{l}\text { Organizational Knowledge } \\
\text { Creation Theory }\end{array}$ & $\begin{array}{l}\text { From case to } \\
\text { methods and } \\
\text { tools }\end{array}$ & $\begin{array}{l}\text { Global Vs Local; Tacit Vs } \\
\text { Explicit Knowledge }\end{array}$ \\
\hline Swanson (2010) & IS Strategy & --- & 5 deliverables \\
\hline $\begin{array}{l}\text { Rosemann et al. } \\
(2004)\end{array}$ & Requirement Engineering & 5 steps & $\begin{array}{l}\text { Organizational needs Vs } \\
\text { Software Capabilities }\end{array}$ \\
\hline
\end{tabular}

According to Pozzebon and Pinsonneault (2005) the role of a consultancy is to translate global knowledge, defined as "generalizable features that may be divorced from particular settings and applied more widely" (p.122) into local knowledge, i.e. practical knowledge that is "highly specific to each particular firm and depends on the firm's employees" (p.122). This approach grounded in the resource-based view (Barney, 1991) fails to detail the key activities required to pass from global to local and vice-versa. Werr and Stjnberg (2003) focus on the importance of translating the experience of a consultant into a set of cases, which are local and explicit knowledge that contributes to the creation of global and explicit knowledge in the form of methods and tools. Such methods and tools are then converted into other cases and improved. This approach follows the stream of organizational knowledge creation theory summarized in Nonaka \& Von Krogh (2009), which focuses more on the dynamic creation of knowledge rather than the type of knowledge created. Swanson (2010) extends the work of Werr and Stjnberg (2003) by identifying five consultancy roles (Business strategy, IT research and analysis, Business process improvement, Systems integration and Business services). Each role is associated to a set of deliverables (in this paper we focus on the deliverables of the Business strategy role, which are a valuable input to this first stage of innovation, by creating a strategic framework for change). This approach, belonging to the field of IS strategy and innovation management, recognizes the role of the consultancy as an IT-broker but fails to explain in detail the process of requirement elicitation. Rosemann et al. (2004) do not address the role of consultancies, but identify two ontologies to be aligned: organizational needs and software capabilities, which we claim to correspond to local and global knowledge. This work, which comes from the literature in requirement engineering, drafts a five step process to align the two ontologies, but it is not concerned about how a consultancy could make a profit from this activity.

In conclusion, the existing research has not yet analyzed how to assess the quality of the global-local translation by a consultancy, how a consultancy can make a profit out of such translation, and what is the role of the customer in such translation. Hence, we derive the following research sub-questions: 
R-SQ1: How can the quality of the global-local knowledge translation process carried out by a IS strategic consultancy be increased.

R-SQ2: How can an IS strategic consultancy gain a sustainable competitive advantage from a high-quality global-local knowledge translation.

R-SQ3: What is the role of the customer in the global-local translation process?

From the literature review we also derive that there is no definitive formulation of the key activities and resources to be profitably used by a IS strategic consultancy, and that the existence of a discrepancy representing this issue can be explained in numerous ways. The choice of explanation determines the nature of the problem resolution. Thus the problem we address could be defined as "wicked" and best to be addressed using a design research methodology, as explained in the next section.

\section{Methodology}

In this section we briefly describe the methodology we used. Based on the relevant literatures, we create an artifact in the form of a model to express the relationship between local and global knowledge. We adopt a design science research methodology and refer to existing guidelines for design theories (Gregor and Jones, 2007), which "give explicit prescriptions on how to design and develop an artifact, whether it is a technological product or a managerial intervention" (p. 312). Therefore we advance in three steps as illustrated in the figure below.
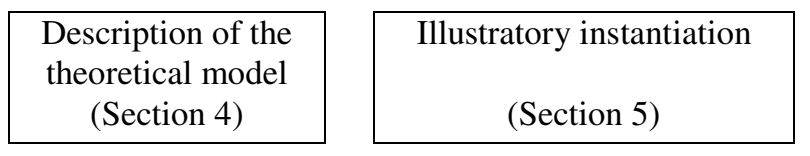

Fig. 1. Following sections
Example of a business model (Section 6)

An information system design theory (ISDT) should define its purpose and scope, i.e. the boundaries of a theory. In our case, the theory relates to knowledge management to support customer retention. In this sense we introduce the representations of the entities of interest in the theory, i.e. constructs. The principles of form and function define the structure, organization, and functioning of the design product or design method. The justificatory knowledge provides an explanation as to why an artifact is constructed as it is and why it works. Accordingly in section 4 we introduce a model indicating how to assess the quality of the local-global knowledge translation. In doing so we ground our claims on existing theories of knowledge management, as well as principles of theory building. In section 5 we illustrate how to derive software requirements from our theoretical model by means of an example derived from the six-month internship in a strategic consultancy and we briefly illustrate our on-going evaluation strategy of testable propositions. In section 6 we present a possible use of our theoretical model by presenting a set of business model components for a consultancy.

\section{The Theoretical Model}

In this section we present a model that addresses our research question. We wish to extend the previous literature trying to explain how to best pass from local knowledge 
to global knowledge. In order to do so, we introduce the notion of quality of the output in the translation process.

Our definition of consultancy benchmarks extends the definition of Werr and Stjnberg (2003) for "cases" i.e. "documents produced in projects, e.g. maps, process and proposals" (p.889). Indeed we identify our benchmarks as ideal types of a typology and we measure them collecting the number of templates used by the consultancy. The benchmarks are collected within a framework, which in the words of Weber (2010) to define a theory, is. "a particular kind of model that is intended to account for some subset of phenomena in the world" (p.3). The concept of theory recalls Pozzebon and Pinsonneault's (2005) idea of global knowledge. According to Weber (2010) the quality of a theory can be evaluated in part and in whole. The quality of the whole framework can be assessed using five criteria: importance, novelty, parsimony, level, falsifiability. The importance of the framework can be measured by the number of clients using it. The novelty of the framework depends on the level of innovation requested by the customer and could have two values. Swanson (2010) claims that customers use consultancies to be at the same level as their competitors, rather than to discover disruptive uses of a new technology. A framework is parsimonious when "it achieves good levels of predictive and explanatory power in relation to its focal phenomena using a small number of constructs, associations, and boundary conditions" (Weber 2010, p.8). The guidelines to create a typology-inspired framework allow for meso-levels of precision. i.e. a good balance between too much precision and too much abstraction. The level of the framework can be measured using the types of IS consulting (Swanson, 2010): business strategy, technology assessment, business process improvement, systems integration, business process support. The falsifiability can be associated to the number of key performance indicators used in the framework. The table for the operationalization of our constructs can now be derived.

Table 2. The constructs of our model

\begin{tabular}{|c|l|l|}
\hline Construct & \multicolumn{1}{|c|}{ Definition } & \multicolumn{1}{|c|}{ Source } \\
\hline $\begin{array}{c}\text { Consultancy } \\
\text { benchmarks }\end{array}$ & $\begin{array}{l}\text { Complex constructs that can be used to } \\
\text { represent holistic configurations of multiple } \\
\text { unidimensional constructs }\end{array}$ & $\begin{array}{l}\text { Doty Glick (1994, } \\
\text { p.233) }\end{array}$ \\
\hline $\begin{array}{c}\text { Framework } \\
\text { Quality }\end{array}$ & $\begin{array}{l}\text { The value of emergent } \text { attributes of the } \\
\text { framework }\end{array}$ & $\begin{array}{l}\text { Adapted from } \\
\text { Weber (2010) }\end{array}$ \\
\hline
\end{tabular}

Table 3. Operationalization of constructs

\begin{tabular}{|l|l|l|}
\hline \multicolumn{1}{|c|}{ Thing: attribute } & \multicolumn{1}{c|}{ Variable } & \multicolumn{1}{c|}{ Values } \\
\cline { 1 - 2 } Consultancy benchmarks & Number of templates & Integer [0:n] \\
\cline { 1 - 2 } Framework Quality: importance & Number of clients & Integer [0:n] \\
\cline { 1 - 1 } Framework Quality: novelty & Disruptive innovation & Boolean [true:false] \\
\cline { 1 - 1 } Framework Quality: parsimony & Framework dimensions & Integer [0:n] \\
\cline { 1 - 1 } Framework Quality: level of interest & IS Levels covered & Integer [0:5] \\
\cline { 1 - 1 } Framework Quality: falsifiability & Key performance indicators & Integer [0:n] \\
\hline
\end{tabular}


Once the constructs are operationalized we state our null hypothesis, which concerns a non-linear relationship between the quality of the framework and the number of consultancy benchmarks. The role of an IT-broker in the IS strategic consultancy is to align two customer's organizational needs and software capabilities. Since those two ontologies are finite sets, the marginal contribution of a new best practice will eventually have to go to zero, since it adds no knowledge.

H0: The positive relationship between number of benchmarks and quality of the consultancy framework is not linear.

One possible trend of such a non-linear function can be derived by considering the framework as a sort of theory. Weber (2010) explains that "as the number of constructs, associations, and boundary conditions in a theory increases, the theory might be better able to predict and explain the focal phenomena. As some point, however, users of the theory will deem it to be too complex. The goal is to achieve high levels of prediction and explanation with a small number of theoretical components (Ockham's Razor)"(p.8). Accordingly one could expect the framework parsimony to follow an inverted quadratic function as illustrated in the figure below.

H1: The positive relationship between number of benchmarks and parsimony of the consultancy framework follows an inverted u-shaped function.

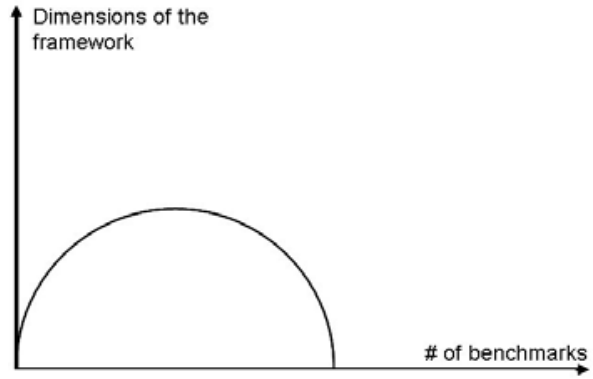

Fig. 2. Example of an inverted U-shape curve

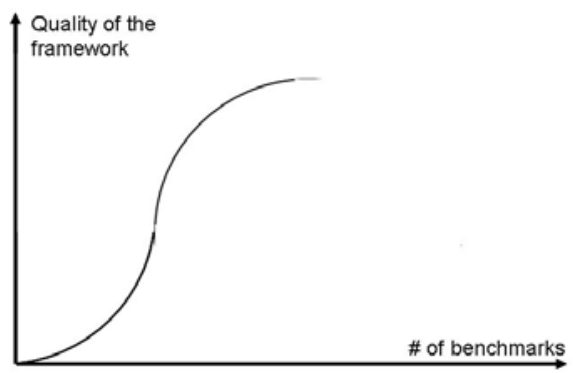

Fig. 3. Example of an S-shaped curve

Another trend is suggested by the literature on innovation, which leads us to believe that the relationship between number of benchmarks and framework quality should follow an S-shaped curve. 


\section{H2: The positive relationship between number of benchmarks and quality of the consultancy framework follows a logistic function.}

Given this theoretical model in the following sections we wish to illustrate the guidelines to test its validity.

\section{Illustratory Instantiation}

In this section we present how we intend to test our theoretical model using a repository for consultancy benchmarks. The figures used for illustratory purpose have been changed from the original images developed during the six-month internship at the consultancy to respect its confidentiality requirements.

Components: Goal oriented requirement engineering allows to express goals, tasks required to achieve the goals, and indicators to measure the task performance. A large amount of work already exists, the most cited being Van Lamsweerde (2002). Therefore we limit ourselves to claim that the first-order constructs of the consultancy framework can be represented using the goal oriented language (GRL) as goals and soft-goals, whereas the best-practices can be modelled as task, as shown in the figure below. To present the tasks in detail we have chosen to use the Use Case Maps (UCM) approach described in Buhr (2002). As illustrated in the figure below a process is composed of various tasks and sub-processes affected to various actors. The elements presented in this figure come from results of a six-month internship in a strategic consulting firm. According to figure 4 the "Earning before Interest and Taxes" is an indicator of the "Profit increase". "Cost reduction" (measured by "Yearly cost") and "Revenue increase" (measured by "Yearly revenues") have a positive effect on "Profit increase". On the cost side the action "Knowledge management" has a positive effect on the element "Best practices", which lowers the "Yearly cost". On the revenue side the action "Customer relationship management" has a positive effect on the soft-goal "Trusted relationship", which increases the yearly revenues. The main reason behind the choice of UCM is the possibility to combine GRL and UCM by means of the Unified Requirements Notation (URN) described in Amyot (2003).

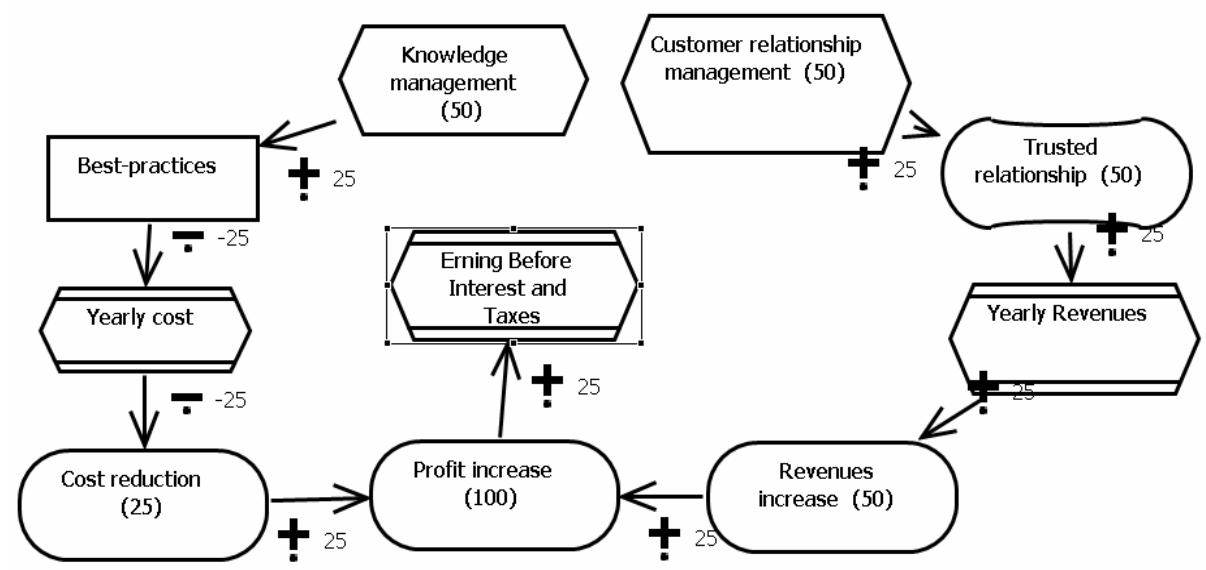

Fig. 4. Example of GRL use to represent profit increase 
Architecture: We use the Eclipse plug-in called jUCMNav to implement our repository. For the moment we limit ourselves to the supporting processes of the strategic consultancy. Use case map (UCM) allows representing the 73 supporting processes in a consistent way, whereas the goal requirement language (GRL) is used to express the goals and soft-goals of the consultancy.

System mutability: The goals in GRL and the tasks in UCM are connected in URN. Once a new task is introduced it has to be linked to a goal to assess its contribution. In the same way, once a new goal is added it has to be linked to the existing set of tasks to assess its feasibility. This phase of the implementation has not been completed yet and will be used to verify our model.

Evaluation strategy: the evaluation of our instantiation is currently ongoing. During the six-month internship a set of iterations was set to formalize the processes of the consultancy. At the end of each iteration an expert from the firm and researchers gathered to assess the quality of the work-in-progress. The first prototype for the processes was created using Visio to respect the existing software approach of the consultancy. Visio's prototype usability was tested through a survey. The second prototype using URN was created in the lab, leaving only the task-goal linking process left to be done by the consultancy. We expect that once we link goals to processes (considered here as benchmarks for consultants) the amount of soft-goals (dimensions of the framework) will follow an inverted u-shape, whereas the KPI, the number of soft-goals and the number of clients using the framework will increase following an S-shape.

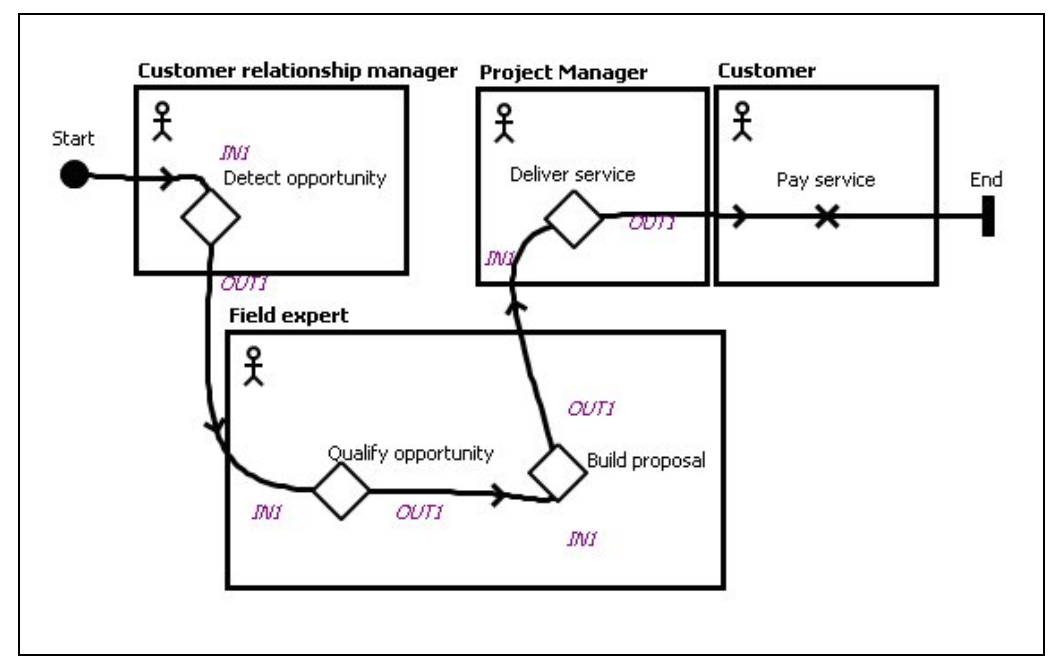

Fig. 5. Example of use case map for contract management

\section{Implementation of Our Model}

In the previous section we illustrated how a consultancy can use its key resources to pass from client's local knowledge in its tacit form to global knowledge under the 
shape URN diagrams. We conclude now by suggesting how this could be profitable for the consultancy. In doing so we consider the consultancy as an example of strategy as a profession associated to a particular business model. The figure below shows that the business model ontology of Osterwalder and Pigneur (2010) states that a company can offer a specific value proposition (VP) by combining key activities (KA), key resources (KR) and key partnership(KP). Such a value proposition is delivered through a channel $(\mathrm{CH})$ to a customer segment $(\mathrm{CS})$, with whom the company establishes a relationship (CR). The difference between the revenue flows (R\$) and the cost structure $(C \$)$ is the profit for the company. In our case the main customer segment (CS) of the consulting firm is composed of the companies using its strategic advice. The value proposition (VP) offered to this customer falls into five types of contributions to innovation with IT identified by Swatson (2010): Business strategy, Technology assessment, Business process improvement, Systems integration and Business support services. According to our research question we focus on the first type of contribution, and we are interested in the risk reduction by minimization of the ontological distance between organizational needs and software capabilities (Rosemann et al. 2004). The consulting provider delivers the channel $(\mathrm{CH})$ services as a project. Each project has to respect a set of quality guidelines defined in accordance with the customer. One could consider the exchanges among the consulting firm and the customer as information economics. Therefore each project requires the consulting provider and the customer to manage a contract under asymmetry of information (Akerlof, 1970). Accordingly, the process is composed of four steps. At $t=1$ the consulting provider knows the quality of the service offered. At $t=2$ the customer offers a price in exchange for service quality, which can be accepted or refused by the consulting provider. At $t=3$ the consulting provider delivers the service. At $t=4$ the customer assesses the quality of the service against the agreement made at $t=2$. If the service quality complies with the agreement, the customer is satisfied and the consulting provider is paid. Regarding the customer relationship (CR) Rhenman (1973) acknowledges that "there is in the consultant-client relationship an element of conflict.[...] Whether he realizes it or not, the consultant will become a pawn in the political game: his presence will always have some effect on the balance of power, sometimes perhaps a good deal." (pp. 160-171). Hence the customer agreement to pay might not be a good proxy for the quality of the service delivery. To address this issue we assume that the customer finds hidden costs after the payment, derived from a shading attitude of the consultant. But in this case the consulting provider is likely to not be hired again. Therefore we focus on project contracts that are managed among consulting firms and customers that have previously worked together, and we intend customer retention as a proxy of trusted relationship among a consultancy and its customers.

Among the key partnerships (KP) of the consulting firm are its customers since they are the source of local knowledge. On the one hand, in the role of information broker the consultancy delivers global knowledge and obtains local knowledge from each customer. On the other hand each customer can decide to hire one consultant. Therefore we identify these as "co-opetition" (Nalebluff and Brandenburger, 1997) relationships among the consultancy and its customers. In this type of this strategic alliance each strategic partners can decided to follow one of the four strategies suggested by Noteboom (2003). Since we limit ourselves to recurrent interactions among a consultancy and a firm, we focus on the so-called "making attractive" strategy, 
which is cooperative and fastening and which depends on mutual trust. The critical resource $(\mathrm{KR})$ is the consultancy framework previously described. The critical activity (KA) is the global-local knowledge translation previously described. The revenue flow $(\mathrm{R} \$)$ emerges from the satisfaction of the customer relative to the quality of the service provided and then the payment of the agreement. As previously mentioned in this paper, we focus on consultant contribution in Business strategy. The costs structure $(C \$)$ mainly emerges from the dynamic transaction cost and human resources. Dynamic transaction cost derives from the inability of the customer to internally create these capabilities (Langlois, 1992). Therefore consultants are more likely to contribute more to the processes by which firms imitate each other, than to those by which firms differentiate themselves (Swanson, 2010).

Table 4. Consultancy as innovation broker

\begin{tabular}{|c|c|c|c|c|}
\hline KR & KA & VP & CR & CS \\
\hline \multirow[t]{2}{*}{$\begin{array}{l}\text { Customer's } \\
\text { local } \\
\text { knowledge }\end{array}$} & $\begin{array}{l}\text { Consultancy/ } \\
\text { customer social } \\
\text { exchange }\end{array}$ & $\begin{array}{l}\text { Relational risk } \\
\text { perceived by the } \\
\text { customer }\end{array}$ & $\begin{array}{l}\text { Consultancy/ customer } \\
\text { relationship recurrence }\end{array}$ & \\
\hline & $\begin{array}{l}\text { KR } \\
\text { Consultancy } \\
\text { benchmarks }\end{array}$ & $\begin{array}{l}\text { Performance risk } \\
\text { reduction } \\
\text { perceived by the } \\
\text { customer }\end{array}$ & $\begin{array}{l}\mathrm{CH} \\
\text { Quality the consultancy } \\
\text { framework }\end{array}$ & \\
\hline
\end{tabular}

\section{Discussions and Conclusions}

In this section we conclude addressing our research sub-questions:

R-SQ1: How is it possible to increase the quality of the global-local translation process which an IS strategic consultancy goes through? In table 3 of section 4 we present a set of five criteria to assess the quality of the consultancy framework and suggest the correlations among customer cases and consultancy framework quality. The idea of framework quality allows a consultancy to find the proper trade-off between the effort required to do the local-global translation and the creation of a competitive advantage.

R-SQ2: How an IS strategic consultancy can gain a sustainable competitive advantage from a high-quality global-local knowledge translation? Section 5 briefly introduces an instantiation of the framework using URN, illustrating how to convert our model into software specifications. Section 6 illustrates how to create a business model using of the consultancy framework.

R-SQ3: What is the role of the customer in the global-local translation process? Section 5 underlines how the customer is also the supplier of new cases. We identify 
a particular relationship between a consultancy and its customers. Both of them aim to access new global/local knowledge. In this co-opetition situation, customer trust is important in the consultancy and is the key for relationship success.

In conclusion we would like to recall our Wizard of $\mathrm{Oz}$ metaphor and the man behind the curtain. Trying to understand in which ways and under which conditions consultants contribute to their clients' learning and knowledge development (and vice versa), we have underlined one way to assess the quality of that contribution and the important role of mutual knowledge exchange to make it sustainable. At times, a consultant is like the Wizard of Oz, whose critical role is to lead the customer towards various quests to make him understand, at the end, that most of what he needs was already in his shoes.

Acknowledgements. The work presented in this paper was supported by the Swiss National Science Foundation (NSF) under grant number 205121-120534.

\section{References}

1. Akerlof, G.A.: The market for "lemons". The Quarterly Journal of Economics 84, 488-500 (1970)

2. Barney, J.B.: Firm resources and sustained competitive advantage. Journal of Management 17, 99-120 (1991)

3. Chen, D.Q.: Information Systems Strategy: Reconceptualization, Measurement, and Implications. MIS Quarterly 34, 233-259 (2010)

4. Doty, D.H., Glick, W.H.: Typologies as a unique form of theory building: Toward improved understanding and modeling. Academy of Management Review 19, 230-251 (1994)

5. Gregor, S., Jones, D.: The Anatomy of a Design Theory. Journal of the Association for Information Systems 8, 312 (2007)

6. Langlois, R.N.: Transaction-cost economics in real time. Industrial and Corporate Change 1, 99-127 (1992)

7. Nalebuff, B., Brandenburger, A.: Co-opetition: Competitive and cooperative business strategies for the digital economy. Strategy \& Leadership 25, 28-35 (1997)

8. Nonaka, I., Von Krogh, G.: Tacit Knowledge and Knowledge Conversion: Controversy and Advancement in Organizational Knowledge Creation Theory. Organization Science 20, 635-652 (2009)

9. Osterwalder, A., Pigneur, Y.: Business Model Generation: A Handbook for Visionaries, Game Changers, and Challengers. Wiley, Chichester (2010)

10. Pozzebon, M., Pinsonneault, A.: Global-local negotiations for implementing configurable packages: The power of initial organizational decisions. The Journal of Strategic Information Systems 14, 121-145 (2005)

11. Rhenman, E., Adler, N.: Organization theory for long-range planning. Wiley, Chichester (1973)

12. Rosemann, M., Vessey, I., Weber, R.: Alignment in enterprise systems implementations: the role of ontological distance. In: Proceedings of the International Conference on Information Systems, Washington, DC, pp. 439-447 (2004)

13. Swanson, E.B.: Consultancies and capabilities in innovating with IT. The Journal of Strategic Information Systems 19, 17-27 (2010) 
14. Weber, R.: Theory Building in the Information Systems Discipline: Some Critical Reflections. In: Presented at the Information Systems Foundations: Theory Building in Information Systems, Canberra, Australia, (September 30, 2010)

15. Werr, A., Stjernberg, T.: Exploring Management Consulting Firms as Knowledge Systems. Organization Studies 24, 881-908 (2003)

16. Whittington, R.: Strategy practice and strategy process: family differences and the sociological eye. Organization Studies 28, 1575 (2007) 